\title{
Effects of telmisartan on office and 24-hour ambulatory blood pressure: an observational study in hypertensive patients managed in primary care
}

This article was published in the following Dove Press journal:

Vascular Health and Risk Management

18 January 2010

Number of times this article has been viewed

\author{
Frederic Kontny' \\ Terje Risanger ${ }^{2}$ \\ Arne Bye ${ }^{3}$ \\ Øyvind Arnesen ${ }^{4}$ \\ Odd Erik Johansen ${ }^{4}$ \\ for the TELMIMORE Study \\ Investigators ${ }^{5}$ \\ 'Dept of Cardiology, Volvat Medical \\ Centre, Oslo, Norway; ${ }^{2}$ Prinsdal \\ Health Centre, Oslo, Norway; ${ }^{3}$ Frosta \\ Health Centre, Frosta, Norway; \\ ${ }^{4}$ Medical Department, Boehringer- \\ Ingelheim Norway KS, Asker, Norway; \\ ${ }^{5}$ The TELMIMORE Study Investigators \\ are listed at the end of the paper
}

Correspondence: Odd Erik Johansen Medical Department, BoehringerIngelheim Norway KS, PO Box 405, 1373 Asker, Norway

Tel +4797817674

Fax +4766761330

Email odd-erik.johansen@boehringeringelheim.com
Purpose: Although elevated blood pressure (BP) predicts future cardiovascular events, recommended BP targets often is not reached in the general community. In a clinical real-life setting we evaluated BP impact and tolerability of the angiotensin-II receptor blocker telmisartan in patients with essential hypertension.

Patients and methods: Patients in this observational study not at target BP started or switched to telmisartan monotherapy ( 40 or $80 \mathrm{mg}$ ) or a fixed-dose combination of telmisartan and hydrochlorothiazide (HCT) $80 \mathrm{mg} / 12.5 \mathrm{mg}$. Office and 24-hour ambulatory BP (AMBP) were measured before and after 8 weeks of treatment and physicians reported perceived drug efficacy and tolerability as "Very good", "Good", "Moderate" or "Bad".

Results: 100 patients (34\% female, 60 years, BMI $29.4 \mathrm{~kg} / \mathrm{m}^{2}$, mean office BP 159/92 mmHg) of whom $38 \%$ were treatment naïve and $30 \%, 17 \%, 9 \%$ and $6 \%$ respectively were on $1,2,3$ or 4 BP-lowering drugs, completed 8 weeks of treatment. The proportion of patients with office BP $<140 / 90 \mathrm{mmHg}$ increased from $3 \%$ to $54 \%$ for systolic $(P<0.001), 38 \%$ to $75 \%$ for diastolic $(P<0.001)$, and $2 \%$ to $45 \%$ for systolic and diastolic BP $(P<0.001)$. A significant effect on BP levels was seen in patients being either treatment naïve or on 1 to 3 BP-lowering drugs at study entry, whereas no BP improvement occurred in those who switched from 4 drugs. Overall, mean 24-hour AMBP was reduced from $141 / 85$ to $131 / 79 \mathrm{mmHg}(P<0.001)$. Drug efficacy and tolerability were perceived as "Very good" or "Good" by $44 \% / 34 \%$ and $66 \% / 27 \%$, respectively. No drug discontinuations or serious adverse events were observed.

Conclusions: In this observational study, telmisartan 40 to $80 \mathrm{mg}$, or the fixed-dose combination telmisartan $80 \mathrm{mg} / \mathrm{HCT} 12.5 \mathrm{mg}$, significantly increased the number of patients reaching target $\mathrm{BP}<140 / 90 \mathrm{mmHg}$ if treatment naïve or previously receiving 1 to $3 \mathrm{BP}-$ lowering drugs. The BP reduction achieved was sustained for 24-hour and treatment tolerability was high.

Keywords: telmisartan, tolerability, efficacy, 24-hour ambulatory blood pressure, observational study

\section{Background}

Elevated blood pressure (BP) increases the risk for cardiovascular (CV) morbidity and mortality ${ }^{1-4}$ in a curvilinear relation, starting at $115 / 75 \mathrm{mmHg}$, irrespective of age and gender. The BP-related CV risk is accentuated in the presence of other $\mathrm{CV}$ risk factors or co-morbidities such as diabetes mellitus, obesity, metabolic syndrome and dyslipidemia. ${ }^{5}$

This is of concern as the prevalence of hypertension is high, eg, $28.4 \%$ in a survey among US residents from $2000,{ }^{6}$ and on the rise; a significant $10 \%$ increase was seen in the National Health and Nutrition Examination Surveys (NHANES) between 1988 and $2004 .^{7}$ The cause for this development is multifactorial, eg, increasing prevalence 
of diabetes and obesity and increased life expectancy, which all are factors associated with increased cumulative lifetime risk for hypertension. ${ }^{5}$

Pharmacological BP-lowering contributes to $\mathrm{CV}$ disease prevention. Hence, several institutional bodies have issued BP treatment guidelines (eg, the Joint National Committee on Prevention, Detection, Evaluation, and Treatment of High Blood Pressure [JNC-VII]), ${ }^{8}$ the American Heart Association $^{9}$ and the European Societies of Hypertension and Cardiology. ${ }^{10}$ Most of these agree on a treatment goal of $<140 / 90 \mathrm{mmHg}$ in uncomplicated essential hypertension. However, despite such guidelines and the prevailing high number of anti-hypertensive agents, ${ }^{11}$ BP treatment goals are often not reached in hypertensive patients. It is believed that only approximately $25 \%$ to $40 \%$ of the treated subjects in the community are at target BP levels, ${ }^{12,13}$ which is in line with the NHANES examination 1999-2000 where only $31.0 \%$ of hypertensive patients were controlled to a BP of $<140 / 90 \mathrm{mmHg} .^{5}$ The cause for this may be both patient and physician related; eg, side effects or low efficacy of BP drugs, physicians resistance to supplement or dose escalate initiated treatment (as often $\geq 2$ BP drugs are needed) and a low public awareness of CV benefits of BP control. ${ }^{3,14}$

In the present study, in a "real-world" setting of hypertensive patients in primary care not at target BP levels we wanted to evaluate BP responses (office- and 24-hour ambulatory-BP (AMBP) profiles), occurrence of side effects, and physicianperceived drug efficacy and tolerability of the oral angiotensin II receptor blocker, telmisartan (Micardis ${ }^{\circledR}$; Boehringer Ingelheim Pharma, Germany). Telmisartan reduces BP by blocking vasoconstriction, sodium retention, and aldosterone and vasopressin production caused by angiotensin II. ${ }^{15}$

\section{Methods}

This was a prospective, nonrandomized, multicenter observational study (The Telmimore study [A clinical survey of the antihypertensive effects of telmisartan in patients with mild-to-moderate hypertension]) of patients recruited by 25 general practitioners (GPs) in the middle, western and south-eastern regions of Norway serving approximately 20000 to 25000 subjects. Patients with essential hypertension not at target BP, who were prescribed telmisartan by the physician on clinical indication, were eligible for inclusion. Informed written consent was obtained from all participants. The study was performed in accordance with the Helsinki Declaration and approved by the Regional Ethical Committee.

Patients were enrolled between June 2006 and June 2007, and remained under the care of the GPs for the duration of the study that was 8 weeks. At enrolment, a general clinical examination was performed and weight, height, data concerning past medical history (including coronary heart disease, diabetes mellitus, hypercholesterolemia, atrial fibrillation, chronic obstructive pulmonary disease, and cerebrovascular disease), and current medication were recorded in a case report form (CRF). Office BP was measured on the non-dominant arm with a random zero mercury sphygmomanometer using appropriate cuff size in sitting position after 5 minutes of rest. A mean of two measurements was recorded. 24-hour AMBP measurements were performed, utilizing an oscillometric equipment, on the nondominant arm using appropriate cuff size (Welch Allyn AMBP 6100, Skaneateles Falls, NY, USA), starting between 10:00 am and 12:00 am. Reading intervals were 15 minutes from 07:00 am to 11:00 pm and 30 minutes from 11:00 pm to 07:00 am. 24-hour AMBP means were computed with weights according to the time interval between successive readings. Recordings with more than $80 \%$ of valid measurements and which had at least one reading per time-period during night-time and early morning hours were considered valid. ${ }^{16}$

At study entry, patients not at target BP either started (if treatment naïve), or were switched to (if already on BP-lowering drugs) treatment with telmisartan $40 \mathrm{mg}$, $80 \mathrm{mg}$, or a fixed-dose combination of telmisartan $80 \mathrm{mg} /$ hydrochlorothiazide (HCT) $12.5 \mathrm{mg}$. The BP effect was evaluated after 8 weeks. At this final visit the same data as on study entry were recorded together with a questionnaire for the GPs to be filled in concerning perceived drug efficacy and tolerability. Answer options on the questionnaire were divided in "Very good", "Good", "Moderate", "Bad" or "Not determined". Possible adverse events during the study were detailed in the CRF.

Data analysis was performed using SPSS statistical software version 16.0 for Windows (SPSS Inc. Chicago, USA). Data on continuous variables are presented as mean and standard deviation unless otherwise stated. Analysis of continuous variables was performed by paired t-test or a bivariate correlation where appropriate. Categorical variables are presented as counts or proportions (\%) and by statistical comparisons of these parameters the chi-square test or Fisher's exact test were utilized. Sample size was determined based on estimated improvements in proportion of subjects at treatment goal from $30 \%$ to $45 \%$. The null hypothesis was based on no difference in this proportion. A total number of 86 participants needed was estimated from a statistical power of $90 \%$ and an alpha error level of 5\%. A two-sided $P$-value of $<0.05$ was regarded as statistically significant. 


\section{Results}

A total of 103 Caucasian patients was enrolled in the study. Three patients were lost to 8 weeks follow-up, thus 100 patients were eligible for statistical analyses. Of these, 38 patients (38\%) were treatment naïve. Baseline characteristics of the study cohort are given in Table 1 . The BP was high (mean systolic BP $159 \pm 13$ and mean diastolic BP $92 \pm 10 \mathrm{mmHg}$ ) irrespective of medical treatment. Mean BMI was high, adjunctive treatment with statins was relatively low despite substantial co-morbidity, and few patients were on treatment with betablockers. Telmisartan monotherapy 40 to $80 \mathrm{mg}$ (mean dosage $52 \mathrm{mg}$ ) was given to 49 patients (49\%) and the fixed-dose telmisartan $80 \mathrm{mg} /$ HCT $12.5 \mathrm{mg}$ to 51 patients (51\%).

\section{Effects on office BP}

Telmisartan treatment for 8 weeks was associated with a statistically significant reduction in systolic and diastolic
$\mathrm{BP}$, both in treatment naïve patients (BP difference $-24 /-14 \mathrm{mmHg}, P<0.001$ for both) and in patients on 1 , 2, or 3 BP-lowering drugs at study entry (BP difference $-7 /-9 \mathrm{mmHg},[P<0.001$ for both $],-26 /-7 \mathrm{mmHg}$ $[P<0.001$ for both $]$, and $-10 /-4 \mathrm{mmHg}[P<0.01$ for systolic BP only] respectively) (Table 2).

The BP reduction (both systolic and diastolic) for the whole cohort tended to be more pronounced in patients given the fixed-dose telmisartan $80 \mathrm{mg} / \mathrm{HCT} 12.5 \mathrm{mg}$ than in those receiving telmisartan monotherapy if previously treated with BP-lowering drugs (Table 3 ). No statistically significant difference in BP was seen in the six patients switching from a previous combination therapy of 4 BP-lowering drugs to a telmisartan based regimen (Table 3).

The proportion of patients at target BP levels of $<140 / 90 \mathrm{mmHg}$ increased from $2 \%$ at study entry to $45 \%$ after 8 weeks of telmisartan treatment, and did not differ between the three telmisartan regimens ( $40 \mathrm{mg}$ : $46 \%$,

Table I Baseline data for 100 hypertensive patients completing 8 weeks of treatment with telmisartan with or without HCT

\begin{tabular}{|c|c|c|c|c|c|c|}
\hline & Total cohort & Treatment-naïve & I BP drug & 2 BP drugs & 3 BP drugs & 4 BP drugs \\
\hline $\mathrm{n}$ & 100 & 38 & 30 & 17 & 9 & 6 \\
\hline Age (years) & $60 \pm 13$ & $54 \pm 12$ & $63 \pm 14$ & $64 \pm 12$ & $65 \pm 9$ & $62 \pm 6$ \\
\hline Gender (female/male) & $34 / 66$ & $16 / 32$ & $12 / 18$ & $5 / 12$ & $1 / 8$ & $0 / 6$ \\
\hline BMI $\left(\mathrm{kg} / \mathrm{m}^{2}\right)$ & $29.4 \pm 4.7$ & $30.4 \pm 5.7$ & $28.4 \pm 3.9$ & $28.0 \pm 4.5$ & $29.8 \pm 2.7$ & $30.7 \pm 4.2$ \\
\hline \multicolumn{7}{|c|}{ Duration of hypertension } \\
\hline$<$ I year & 39 (39\%) & $29(76 \%)$ & $10(33 \%)$ & $0(0 \%)$ & $0(0 \%)$ & $0(0 \%)$ \\
\hline I-5 years & $24(24 \%)$ & $6(16 \%)$ & $12(40 \%)$ & $5(29 \%)$ & $0(0 \%)$ & I (I7\%) \\
\hline$>5$ years & 37 (37\%) & $3(8 \%)$ & $8(27 \%)$ & $12(7 \mid \%)$ & $9(100 \%)$ & $5(83 \%)$ \\
\hline \multicolumn{7}{|l|}{ Concomitant disease } \\
\hline Coronary heart disease & II (II\%) & $0(0 \%)$ & $2(7 \%)$ & $3(18 \%)$ & $4(44 \%)$ & $2(33 \%)$ \\
\hline Cerebrovascular disease & $5(5 \%)$ & I (4\%) & $3(10 \%)$ & I (6\%) & $0(0 \%)$ & $0(0 \%)$ \\
\hline Atrial fibrillation & $5(5 \%)$ & $0(0 \%)$ & $2(7 \%)$ & $2(12 \%)$ & $0(0 \%)$ & I (I7\%) \\
\hline Diabetes mellitus & $10(10 \%)$ & $6(16 \%)$ & $2(7 \%)$ & $0(0 \%)$ & $0(0 \%)$ & $2(33 \%)$ \\
\hline COPD & $6(6 \%)$ & $3(8 \%)$ & $3(10 \%)$ & $0(0 \%)$ & $0(0 \%)$ & $0(0 \%)$ \\
\hline Dyslipidemia $^{\mathrm{a}}$ & $26(26 \%)$ & $5(13 \%)$ & $6(20 \%)$ & $4(24 \%)$ & $7(78 \%)$ & $4(67 \%)$ \\
\hline \multicolumn{7}{|c|}{ Previous treatment and BP related parameters } \\
\hline Beta-blockers & $15(15 \%)$ & $0(0 \%)$ & 2 & $6(35 \%)$ & $3(33 \%)$ & $4(67 \%)$ \\
\hline Diuretics & $32(32 \%)$ & $0(0 \%)$ & 13 & 7 (4I\%) & $8(89 \%)$ & $4(67 \%)$ \\
\hline ARB & $29(29 \%)$ & $0(0 \%)$ & 9 & $8(48 \%)$ & 7 (78\%) & $5(83 \%)$ \\
\hline ACE inhibitor & $8(8 \%)$ & $0(0 \%)$ & 2 & $4(24 \%)$ & $2(22 \%)$ & $0(0 \%)$ \\
\hline $\mathrm{CCB}$ & 18 (I8\%) & $0(0 \%)$ & 3 & $4(24 \%)$ & $6(67 \%)$ & $5(83 \%)$ \\
\hline Other & $13(13 \%)$ & $0(0 \%)$ & I & $5(29 \%)$ & I (II\%) & $6(100 \%)$ \\
\hline Sys BP (mmHg) & $159 \pm 13$ & $160 \pm 12$ & $155 \pm 13$ & $163 \pm 11$ & $156 \pm 11$ & $162 \pm 19$ \\
\hline Dia BP $(m m H g)$ & $92 \pm 10$ & $97 \pm 9$ & $91 \pm 9$ & $86 \pm 9$ & $88 \pm 11$ & $90 \pm 6$ \\
\hline HR (bpm) & $74 \pm 10$ & $76 \pm 10$ & $71 \pm 12$ & $70 \pm 8$ & $77 \pm 9$ & $79 \pm 7$ \\
\hline
\end{tabular}

${ }^{\mathrm{a}}$ On statin therapy.

Notes: Data are given as mean \pm SD (continuous variables) and as counts ( $n$ ) or \% (categorical variables).

Abbreviations: HCT, hydrochlorothiazide; BP, blood pressure; BMI, body mass index; COPD, chronic obstructive pulmonary disease; ARB, angiotensin II receptor blocker; ACE, angiotensin converting enzyme; $C C B$, calcium channel blocker; sys, systolic; dia, diastolic; HR, heart rate; bpm, beats per minute. 
Table 2 Impact on office BP 8 weeks after initiating or switching to telmisartan with or without HCT (any regimen) according to baseline number of BP-lowering drugs

\begin{tabular}{lllllll}
\hline & Total cohort & Treatment-naïve & I BP drug & 2 BP drugs & 3 BP drugs & 4 BP drugs \\
\hline $\mathrm{n}$ & 100 & 38 & 30 & 17 & 9 & 6 \\
Baseline sys BP $(\mathrm{mmHg})$ & $159 \pm 13$ & $161 \pm 13$ & $155 \pm 13$ & $163 \pm 11$ & $156 \pm 11$ & $162 \pm 19$ \\
Study end sys BP $(\mathrm{mmHg})$ & $139 \pm 14$ & $137 \pm 15$ & $138 \pm 14$ & $137 \pm 11$ & $146 \pm 13$ & $153 \pm 11$ \\
$\Delta$ sys BP $(\mathrm{mmHg})$ & $-20 \pm 16^{* * *}$ & $-24 \pm 18^{* * *}$ & $-17 \pm 16^{* * *}$ & $-26 \pm 13^{* * *}$ & $-10 \pm 9 * *$ & $-9 \pm 12$ \\
Baseline dia BP (mmHg) & $92 \pm 10$ & $97 \pm 9$ & $91 \pm 9$ & $86 \pm 9$ & $88 \pm 11$ & $90 \pm 6$ \\
Study end dia BP (mmHg) & $82 \pm 9$ & $83 \pm 9$ & $81 \pm 7$ & $79 \pm 7$ & $77 \pm 9$ & $91 \pm 11$ \\
$\Delta$ dia BP $(\mathrm{mmHg})$ & $-10 \pm 10^{* * *}$ & $-14 \pm 10^{* * *}$ & $-9 \pm 10^{* * *}$ & $-7 \pm 7^{* * *}$ & $-4 \pm 7$ & $2 \pm 4$ \\
Baseline HR (bpm) & $74 \pm 10$ & $76 \pm 10$ & $71 \pm 12$ & $70 \pm 8$ & $77 \pm 9$ & $79 \pm 7$ \\
Study end HR (bpm) & $70 \pm 12$ & $71 \pm 9$ & $69 \pm 11$ & $70 \pm 8$ & $79 \pm 10$ & $63 \pm 28$ \\
$\Delta$ HR (bpm) & $-3 \pm 12^{* *}$ & $-5 \pm 11^{* *}$ & $-2 \pm 14$ & $0 \pm 10$ & $2 \pm 8$ & $-16 \pm 33$ \\
\hline
\end{tabular}

Notes: Data are given as mean \pm SD.

$* P<0.05, * * P<0.01$, ***P $<0.001$.

Abbreviations: HCT, hydrochlorothiazide; sys, systolic; BP, blood pressure; dia, diastolic; $\Delta$, delta (ie, BP change from baseline to study end); HR, heart rate; bpm, beats per minute.

$80 \mathrm{mg}: 43 \%, 80 \mathrm{mg} / \mathrm{HCT} 12.5 \mathrm{mg}: 43 \%$ ) (Table 4). The corresponding increase in the proportion reaching systolic BP target only was 3\% to 54\%, and diastolic BP target only $38 \%$ to $75 \%(P<0.001$ for all comparisons) (Table 4$)$.

\section{Effects on 24-hour AMBP}

In total, 75 patients (75\%) agreed to have 24-hour AMBP measurements performed. The baseline characteristics of these did not differ significantly from those of the total cohort. Data were lacking for 5 patients at baseline and for 1 patient at follow-up. Thus, 24-hour AMBP recordings were available for statistical analyses in 69 patients.

Telmisartan treatment for 8 weeks was associated with a statistically significant reduction in mean 24-hour AMBP in the whole study cohort (mean systolic/diastolic BP baseline: $141 / 85 \mathrm{mmHg}$; at 8 weeks: $131 / 79 \mathrm{mmHg}, P<0.001$ for both, Figure 1a). Furthermore, in treatment naïve patients (Figure 1b), as well as in those on 2 BP-lowering drugs at study entry (Figure 1d), a significant reduction for both 24-hour mean systolic and diastolic BP was observed, whereas in patients switching from 1 study drug to telmisartan a significant reduction was seen only for the mean 24-hour diastolic BP (Figure 1c), with a trend for systolic BP reduction $(P=0.085)$. There was a positive correlation between 8-week changes in systolic office and mean 24-hour AMBP $(\mathrm{r}=0.54, P<0.001, \mathrm{n}=69)$. No impact was seen on mean 24-hour heart rate (baseline $73.6 \pm 12.2$ vs $74.1 \pm 12.1$ at 8 weeks).

\section{Tolerability and safety}

Telmisartan was classified as being efficacious and well tolerated by most GPs ("Very good": $44 \%$ and $66 \%$, and

Table 3 Effect of telmisartan therapy on office BP at 8 weeks according to baseline number of BP-lowering drugs

\begin{tabular}{|c|c|c|c|c|c|c|c|c|c|}
\hline & \multicolumn{3}{|c|}{ Telmisartan 40 mg } & \multicolumn{3}{|c|}{ Telmisartan 80 mg } & \multicolumn{3}{|c|}{ Telmisartan 80 mg/HCT 12.5 mg } \\
\hline & $\mathbf{n}$ & $\begin{array}{l}\Delta \text { sys BP } \\
(\mathrm{mmHg})\end{array}$ & $\begin{array}{l}\Delta \text { dia BP } \\
(\mathrm{mmHg})\end{array}$ & $\mathbf{n}$ & $\begin{array}{l}\Delta \text { sys BP } \\
(\mathrm{mmHg})\end{array}$ & $\begin{array}{l}\Delta \text { dia BP } \\
(\mathrm{mmHg})\end{array}$ & $\mathbf{n}$ & $\begin{array}{l}\Delta \text { sys BP } \\
(\mathrm{mmHg})\end{array}$ & $\begin{array}{l}\Delta \text { dia BP } \\
(\mathrm{mmHg})\end{array}$ \\
\hline Total cohort & 28 & $-18 \pm 17^{* * *}$ & $-9 \pm 11 * * *$ & 21 & $-18 \pm 20 * * *$ & $-10 \pm 11 * * *$ & 51 & $-22 \pm 14 * * *$ & $-9 \pm 10 * * *$ \\
\hline Treatment-naïve & 19 & $-18 \pm 18^{* * *}$ & $-11 \pm 10^{* * *}$ & 6 & $-28 \pm 24^{*}$ & $-19 \pm 15^{*}$ & 13 & $-30 \pm 12 * * *$ & $-15 \pm 8 * * *$ \\
\hline I BP drug & 5 & $-14 \pm 16$ & $-5 \pm 10$ & 10 & $-9 \pm 13$ & $-7 \pm 7^{*}$ & 15 & $-23 \pm 15^{* * *}$ & $-13 \pm 11 * * *$ \\
\hline 2 BP drugs & 3 & $-30 \pm 9 *$ & $-10 \pm 13$ & 4 & $-29 \pm 23$ & $-8 \pm 6$ & 10 & $-23 \pm 10 * * *$ & $-7 \pm 5 * *$ \\
\hline 3 BP drugs & 1 & -2 & 6 & I & -10 & I & 7 & $-12 \pm 10^{*}$ & $-6 \pm 6 *$ \\
\hline 4 BP drugs & 0 & N/A & N/A & 0 & $\mathrm{~N} / \mathrm{A}$ & $\mathrm{N} / \mathrm{A}$ & 6 & $-9 \pm 12$ & $2 \pm 9$ \\
\hline
\end{tabular}

Notes: Data are given as mean \pm SD and as counts $(n)$.

$* P<0.05$, $* * P<0.01$, $* * * P<0.001$.

Abbreviations: HCT, hydrochlorothiazide; $\Delta$, delta; sys, systolic; dia, diastolic; BP, blood pressure; N/A, not applicable. 
Table 4 Percentages of patients within target office BP $(<140 / 90 \mathrm{mmHg})$ at baseline and study end (after 8 weeks of telmisartan with or without HCT) according to BP therapy at study entry

\begin{tabular}{|c|c|c|c|c|c|c|}
\hline & Total cohort & Treatment naïve & I BP drug & 2 BP drugs & 3 BP drugs & 4 BP drugs \\
\hline$n$ & 100 & 38 & 30 & 17 & 9 & 6 \\
\hline $\begin{array}{l}\text { Baseline sys } \\
\mathrm{BP}<140 \mathrm{mmHg}\end{array}$ & $3 \%$ & $0 \%$ & $7 \%$ & $0 \%$ & $0 \%$ & $17 \%$ \\
\hline $\begin{array}{l}8 \text { weeks sys } \\
\mathrm{BP}<140 \mathrm{mmHg}\end{array}$ & $54 \% * * *$ & $61 \% * * *$ & $57 \% * * *$ & $59 \% * *$ & $33 \% \S$ & $0 \%$ \\
\hline $\begin{array}{l}\text { Baseline dia } \\
\mathrm{BP}<90 \mathrm{mmHg}\end{array}$ & $38 \%$ & $18 \%$ & $40 \%$ & $65 \%$ & $56 \%$ & $50 \%$ \\
\hline $\begin{array}{l}8 \text { weeks dia } \\
\mathrm{BP}<90 \mathrm{mmHg}\end{array}$ & $75 \% * * *$ & $76 \% * * *$ & $80 \% * *$ & $88 \%$ & $67 \%$ & $33 \%$ \\
\hline $\begin{array}{l}\text { Baseline sys/dia } \\
\mathrm{BP}<\text { I } 40 / 90 \mathrm{mmHg}\end{array}$ & $2 \%$ & $0 \%$ & $3 \%$ & $0 \%$ & $0 \%$ & $17 \%$ \\
\hline $\begin{array}{l}8 \text { weeks sys/dia } \\
\mathrm{BP}<\mathrm{I} 40 / 90 \mathrm{mmHg}\end{array}$ & $45 \% * * *$ & $50 \% * * *$ & $47 \% * *$ & $53 \% * * *$ & $33 \% \S$ & $0 \%$ \\
\hline
\end{tabular}

$* * P<0.01$, ***P $<0.001 ; \$ P=0.059$

Abbreviations: BP, blood pressure; $\mathrm{HCT}$, hydrochlorothiazide.

"Good": 34\% and 27\%, respectively) (Table 5). Serious adverse events did not occur and no patients discontinued the treatment. Adverse events occurred in 9 cases: bronchitis, enteritis, arthralgia, rhinitis, mouth dryness, hypotension, lethargy, pollakissuria, and tiredness, of which the latter 5 were assumed by the GPs as potentially being drug related.

\section{Discussion}

Starting telmisartan (either monotherapy in a dosage of 40 to $80 \mathrm{mg}$, or a fixed-dose of telmisartan $80 \mathrm{mg} / \mathrm{HCT} 12.5 \mathrm{mg}$ ) did significantly improve BP in patients both previously treatment naïve and in those on treatment with 1, 2 or 3 BPlowering drugs. This indicates that telmisartan, with or without HCT, has a potent BP-lowering effect that can be useful in a substantial number of patients with arterial hypertension.

The treatment response in the current study is concordant with results from other series exploring the effect of telmisartan in a community setting. ${ }^{17,18}$ This applies also to the high tolerability and low incidence of side effects seen in our study. The observed inverse relation between treatment effect and number of previous BP drugs used is not surprising, as many patients with BP polypharmacy in fact do have a refractory hypertension which also could apply to telmisartan.

As anticipated, the proportion of patients treated to target at study entry was low (2\%), however a substantial number had had their disease for many years $(37 \%>5$ years, $24 \%$ 1 to 5 years) and $62 \%$ were receiving 1 to 4 BP-lowering drugs. Although the observed treatment effects of switching to telmisartan, with or without HCT, for those already on 1 to 3 BP-lowering drugs in most cases were reassuring, a substantial number of patients (55\%) still was not at target after 8 weeks. Generic limitations of observational studies such as a relatively short treatment period and lack of a predefined treatment algorithm including provision of guidelines for dose escalation may have contributed to this. However, clinical experience indicates that target values for BP may be difficult to reach for a substantial number of patients also in the "real world". ${ }^{12,13}$

24-hour AMBP measurements as a means for more optimal BP control are probably underused in clinical practice. In the current study we found it feasible to apply this method in a GP setting, and other trials have shown an educational value of this procedure even for the patient. ${ }^{19}$ Furthermore, 24-hour AMBP, and especially 24-hour systolic BP, has been shown to have prognostic information above and beyond that of office BP. ${ }^{20}$ Thus, a more liberal use of this method in primary care should be advocated. ${ }^{21}$

The observed underuse of statins is in accordance with several surveys indicating that in the general community probably as much as $75 \%$ of patients are not treated according to clinical guidelines. ${ }^{12}$

Limitations of the study, apart for generic limitations with any observational study, include the question whether the cohort is representative of the general hypertensive population. The baseline characteristics including co-morbidity indicate that this is true. Another limitation is that we can not rule out whether similar results could have been obtained by conducting this study with another design or by dose escalating the current used drugs or by add-on of other drugs, since we have no 
A

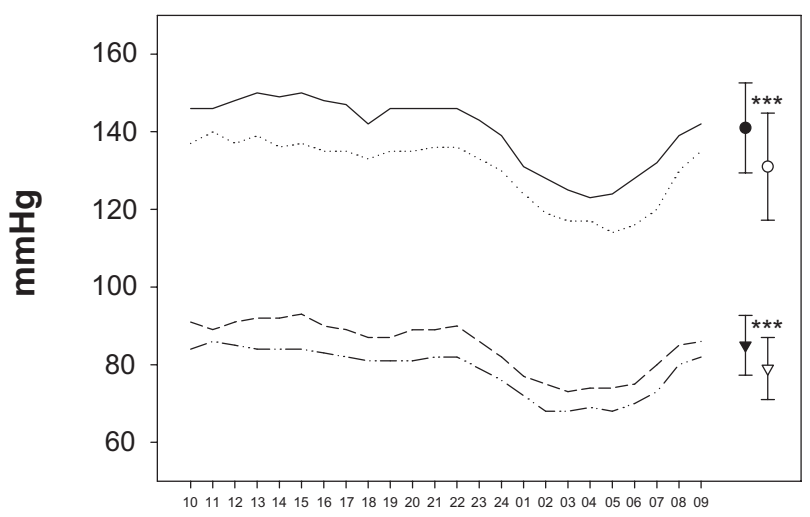

C

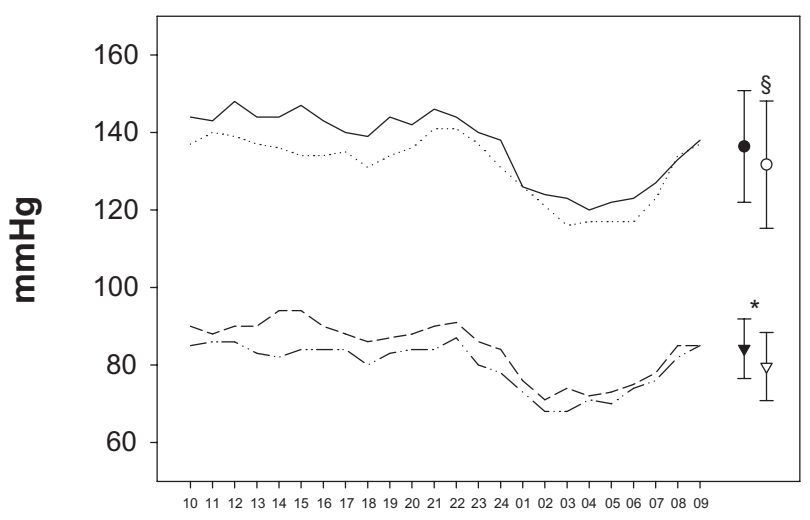

B

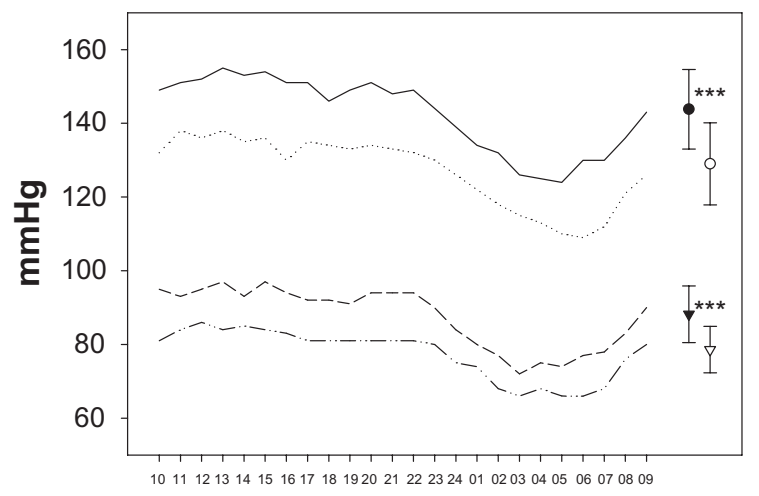

D

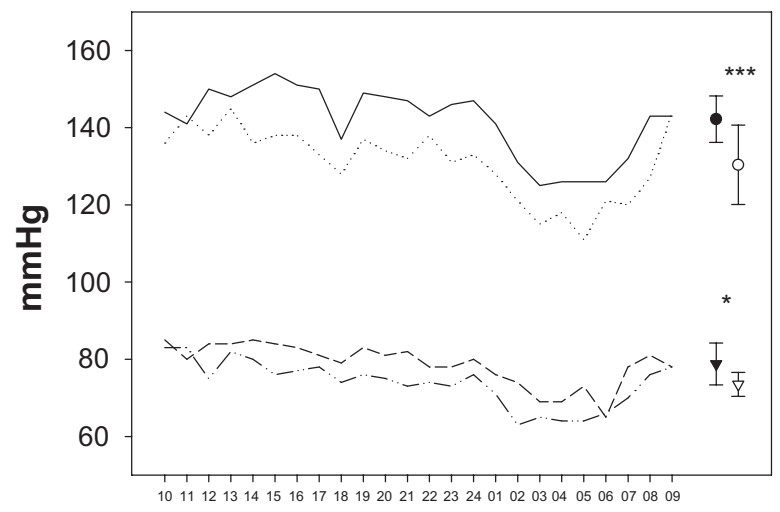

\section{E}

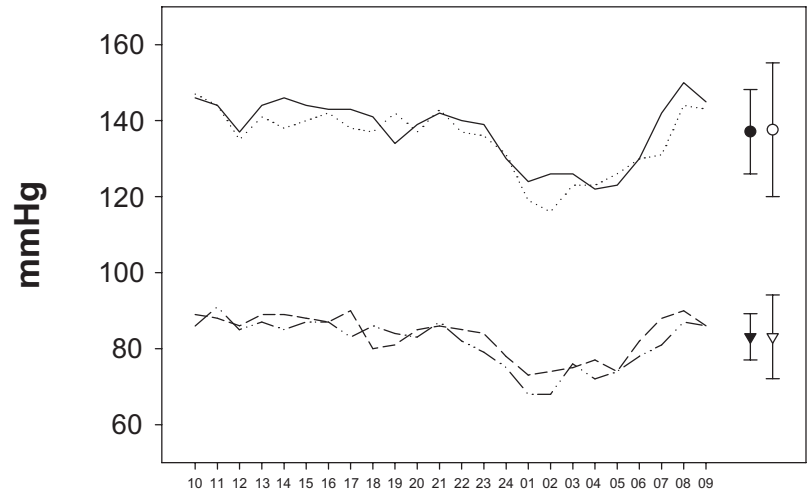

Figure I 24-hour ambulatory BP incl. mean \pm SD at baseline and study end in $\mathbf{A})$ total cohort $(\mathrm{n}=69)$; and according to number of BP-lowering drugs at baseline: B) none $(n=31)$, C) $I(n=17)$, D) $2(n=9)$ and E) 3 or $4(n=12)$ drugs.

Notes: - Baseline hourly sys BP, $\cdots$ 8-weeks hourly sys BP, --- Baseline hourly dia BP, --- 8-weeks hourly dia BP, $\bullet$ Baseline 24-hour sys BP, $\bigcirc$ 8-weeks 24 -hour sys BP, $\nabla$ Baseline 24-hour dia BP, $\nabla$ 8-weeks 24-hour dia $B P, * P<0.05$, $* * * P<0.00 \mathrm{I},{ }^{\circledR} P=0.085$.

Abbreviations: sys, systolic; BP, blood pressure; dia, diastolic.

control group; we also did not assess treatment response based on what type of BP-lowering drug(s) were used (eg, calcium channel blockers, angiotensin receptor blockers, angiotensin conververting enzyme inhibtors) prior to the switch. Other limiting factors include the relatively small sample size, although this was fairly large for a 24-hour AMBP study. Further, an aspect that could limit the treatment response is that among included subjects, some were already at or near BP treatment targets at study entry. On the other hand, this "underevaluation" probably are balanced with the phenomenona of the open nature of the study, which was unavoidable, that could potentially lead to an impact on patients' motivation to "do well" (the Hawthorne effect), thereby overestimating the treatment effect. 
Table 5 Eight-week incidence of adverse events and prescribing physician's subjective evaluation of efficacy and tolerability according to telmisartan treatment regimen

\begin{tabular}{|c|c|c|c|c|}
\hline & Total cohort & 40 mg telmisartan & 80 mg telmisartan & $\begin{array}{l}80 \mathrm{mg} \text { telmisartan/ } \\
\text { I } 2.5 \mathrm{mg} \mathrm{HCT}\end{array}$ \\
\hline $\mathrm{n}$ & 100 & 28 & 21 & 51 \\
\hline \multicolumn{5}{|l|}{ Adverse events } \\
\hline Serious AE & $0(0 \%)$ & $0(0 \%)$ & $0(0 \%)$ & $0(0 \%)$ \\
\hline Minor AE & $9(9 \%)$ & $7(25 \%)$ & $0(0 \%)$ & $2(4 \%)$ \\
\hline \multicolumn{5}{|c|}{ Treatment efficacy as judged by the prescribing physician } \\
\hline Very good & 44 (44\%) & II (39\%) & $9(43 \%)$ & $24(47 \%)$ \\
\hline Good & 34 (34\%) & $12(43 \%)$ & $8(38 \%)$ & $14(27 \%)$ \\
\hline Moderate & $13(13 \%)$ & I (3\%) & $3(14 \%)$ & $9(18 \%)$ \\
\hline Bad & $5(5 \%)$ & I (3\%) & I (5\%) & $3(6 \%)$ \\
\hline Not determined & $4(4 \%)$ & $3(8 \%)$ & $0(0 \%)$ & $\mathrm{I}(2 \%)$ \\
\hline \multicolumn{5}{|c|}{ Treatment tolerability as judged by the prescribing physician } \\
\hline Very good & $66(66 \%)$ & $18(64 \%)$ & $13(62 \%)$ & $35(69 \%)$ \\
\hline Good & $27(27 \%)$ & $5(18 \%)$ & $8(38 \%)$ & $14(27 \%)$ \\
\hline Moderate & $4(4 \%)$ & $3(8 \%)$ & $0(0 \%)$ & $\mathrm{I}(2 \%)$ \\
\hline Bad & $0(0 \%)$ & $0(0 \%)$ & $0(0 \%)$ & $0(0 \%)$ \\
\hline Not determined & $3(3 \%)$ & $2(7 \%)$ & $0(0 \%)$ & I (2\%) \\
\hline
\end{tabular}

Abbreviations: $\mathrm{AE}$, adverse events; $\mathrm{HCT}$, hydrochlorthiazid.

In conclusion, in this observational study, 8 weeks treatment with telmisartan 40 to $80 \mathrm{mg}$ or the fixed-dose combination telmisartan $80 \mathrm{mg} / \mathrm{HCT} 12.5 \mathrm{mg}$ significantly reduced $\mathrm{BP}$ in patients with hypertension being either treatment naïve or switching from 1 to 3 other BP-lowering drugs. The proportion of patients reaching target $\mathrm{BP}<140 / 90 \mathrm{mmHg}$ was also significantly increased with telmisartan, with or without HCT, therapy. BP-lowering effects were sustained for 24 hours and treatment tolerability was high.

\section{TELMIMORE study investigators}

Bakken J, Baloch SM, Berz A, Blatter-Krog Strømme M, Bye A, D'Angelo GE, Folven A, Gorski Z, Humborstad BJ, Karsten DO, Langaker KE, Landmark NE, Leraand N, Lunde S, Nicolaisen B, Onsum H, Parvaiz R, Risanger T, Råheim GA, Storvand E, Ulvan M, Walaas K, Wear-Hansen HG, WesselAas T, Aaserud E.

\section{Disclosures}

F Kontny: Advisory Board fees from AstraZeneca, Boehringer-Ingelheim. Consulting fees from Astra-Zeneca, Boehringer-Ingelheim, Sanofi-Aventis. Grant support from Merck Sharp and Dohme, Perseus Proteomics Inc. Lecture fees from AstraZeneca, Bristol-Myers Squibb, BoehringerIngelheim, Eli-Lilly, Pfizer, Sanofi-Aventis.
T Risanger: Study investigator fees from Boehringer Ingelheim.

A Bye: Advisory Board fees from Astra-Zeneca. Study investigator fees from Merck Sharp and Dohme, Glaxo-Smith Kline and Boehringer Ingelheim.

$\varnothing$ Arnesen: Employee of Boehringer Ingelheim Norway KS.

OE Johansen: Employee of Boehringer Ingelheim Norway KS and associated post-doctoral researcher at Medical department, Vestre Viken, Asker and Baerum Hospital, Norway.

This study was funded by Boehringer Ingelheim Norway KS. The study sponsor was responsible for the data collection and analyses. All data were made available to the writing committee (FK, TR, AB, ØA, OEJ) that in collaboration developed the manuscript and jointly agreed to submit it for publication.

\section{Acknowledgments}

We thank Dr Merete Dahl, Ms Anne-Lise Evensen, Ms Mona Irene Andersen and Mr Jorge Lizano for their contribution in data collection and management, and the study patients for participation.

\section{References}

1. Selmer R. Blood pressure and twenty-year mortality in the City of Bergen, Norway. Am J Epidemiol. 1992;136:428-440.

2. Age-specific relevance of usual blood pressure to vascular mortality: a meta-analysis of individual data for one million adults in 61 prospective studies. Lancet. 2002;360:1903-1913. 
3. Wang TJ, Vasan RS. Epidemiology of uncontrolled hypertension in the United States. Circulation. 2005;112:1651-1662.

4. Peterson JC, Adler S, Burkart JM, et al. Blood pressure control, proteinuria, and the progression of renal disease: The Modification of Diet in Renal Disease Study. Ann Intern Med. 1995;123:754-762.

5. Hajjar I, Kotchen TA. Trends in prevalence, awareness, treatment, and control of hypertension in the United States, 1988-2000. JAMA. 2003;290:199-206.

6. Fields LE, Burt VL, Cutler JA, et al. The burden of adult hypertension in the United States 1999 to 2000: A rising tide. Hypertension. 2004;44:398-404.

7. Ostchega Y, Dillon CF, Hughes JP, et al. Trends in hypertension prevalence, awareness, treatment, and control in Older US Adults: Data from the National Health and Nutrition Examination Survey 1988 to 2004. J Am Geriatr Soc. 2007;55:1056-1065.

8. Chobanian AV, Bakris GL, Black HR, et al. Seventh Report of the Joint National Committee on Prevention, Detection, Evaluation, and Treatment of High Blood Pressure. Hypertension. 2003;42:1206-1252.

9. Rosendorff C, Black HR, Cannon CP, et al. Treatment of hypertension in the prevention and management of ischemic heart disease: a scientific statement From the American Heart Association Council for High Blood Pressure Research and the Councils on Clinical Cardiology and Epidemiology and Prevention. Circulation. 2007;115:2761-2788.

10. Task FM, Mancia G, De Backer G, et al. 2007 Guidelines for the management of arterial hypertension: The Task Force for the Management of Arterial Hypertension of the European Society of Hypertension (ESH) and of the European Society of Cardiology (ESC). Eur Heart J. 2007;28:1462-1536.

11. Psaty BM, Lumley T, Furberg CD, et al. Health outcomes associated with various antihypertensive therapies used as first-line agents: a network meta-analysis. JAMA. 2003;289:2534-2544.
12. Geller JC, Cassens S, Brosz M, et al. Achievement of guideline-defined treatment goals in primary care: the German Coronary Risk Management (CoRiMa) study. Eur Heart J. 2007;28:3051-3058.

13. Nieto FJ, Alonso J, Chambless LE, et al. Population awareness and control of hypertension and hypercholesterolemia. The Atherosclerosis Risk in Communities study. Arch Intern Med. 1995;155:677-684.

14. Tanaka T, Okamura T, Yamagata $Z$, et al. Awareness and treatment of hypertension and hypercholesterolemia in Japanese Workers: The High-Risk and Population Strategy for Occupational Health Promotion (HIPOP-OHP) Study. Hypertens Res. 2007;30:921-928.

15. Sharpe M, Jarvis B, Goa KL. Telmisartan: a review of its use in hypertension. Drugs. 2001;61:1501-1529.

16. O'Brien E, Asmar R, Beilin L, et al. European Society of Hypertension recommendations for conventional, ambulatory and home blood pressure measurement. J Hypertens. 2003;21:821-848.

17. Michel MC, Bohner H, Köster J, et al. U. Safety of telmisartan in patients with arterial hypertension : an open-label observational study. Drug Saf. 2004;27:335-344.

18. White WB, Weber MA, Davidai G, et al. Ambulatory blood pressure monitoring in the primary care setting: assessment of therapy on the circadian variation of blood pressure from the MICCAT-2 Trial. Blood Press Monit. 2005;10:157-163.

19. Mallion JM, de Gaudemaris R, Baguet JP, et al. Acceptability and tolerance of ambulatory blood pressure measurement in the hypertensive patient. Blood Press Monit. 1996;1:197-203.

20. Conen D, Bamberg F. Noninvasive 24-h ambulatory blood pressure and cardiovascular disease: a systematic review and meta-analysis. J Hypertens. 2008;26:1290-1299.

21. Verdecchia P, Angeli F, Mazzotta G, et al. G. Home blood pressure measurements will not replace 24-hour ambulatory blood pressure monitoring. Hypertension. 2009;54:188-195.
Vascular Health and Risk Management

\section{Publish your work in this journal}

Vascular Health and Risk Management is an international, peerreviewed journal of therapeutics and risk management, focusing on concise rapid reporting of clinical studies on the processes involved in the maintenance of vascular health; the monitoring, prevention and treatment of vascular disease and its sequelae; and the involvement of

\section{Dovepress}

metabolic disorders, particularly diabetes. This journal is indexed on PubMed Central and MedLine. The manuscript management system is completely online and includes a very quick and fair peer-review system, which is all easy to use. Visit http://www.dovepress.com/ testimonials.php to read real quotes from published authors. 